Thermochemical

Process

Development Unit

\title{
Researching Fuels from Biomass
}

\section{Highlights}

Thermochemical conversion technologies convert biomass and its residues to fuels and chemicals using gasification and pyrolysis.

Gasification entails heating biomass and results in a mixture of carbon monoxide and hydrogen, known as syngas. Pyrolysis, which is heating biomass in the absence of oxygen, produces liquid pyrolysis oil.

Both syngas and pyrolysis oil can be chemically converted into clean, renewable transportation fuels and chemicals.
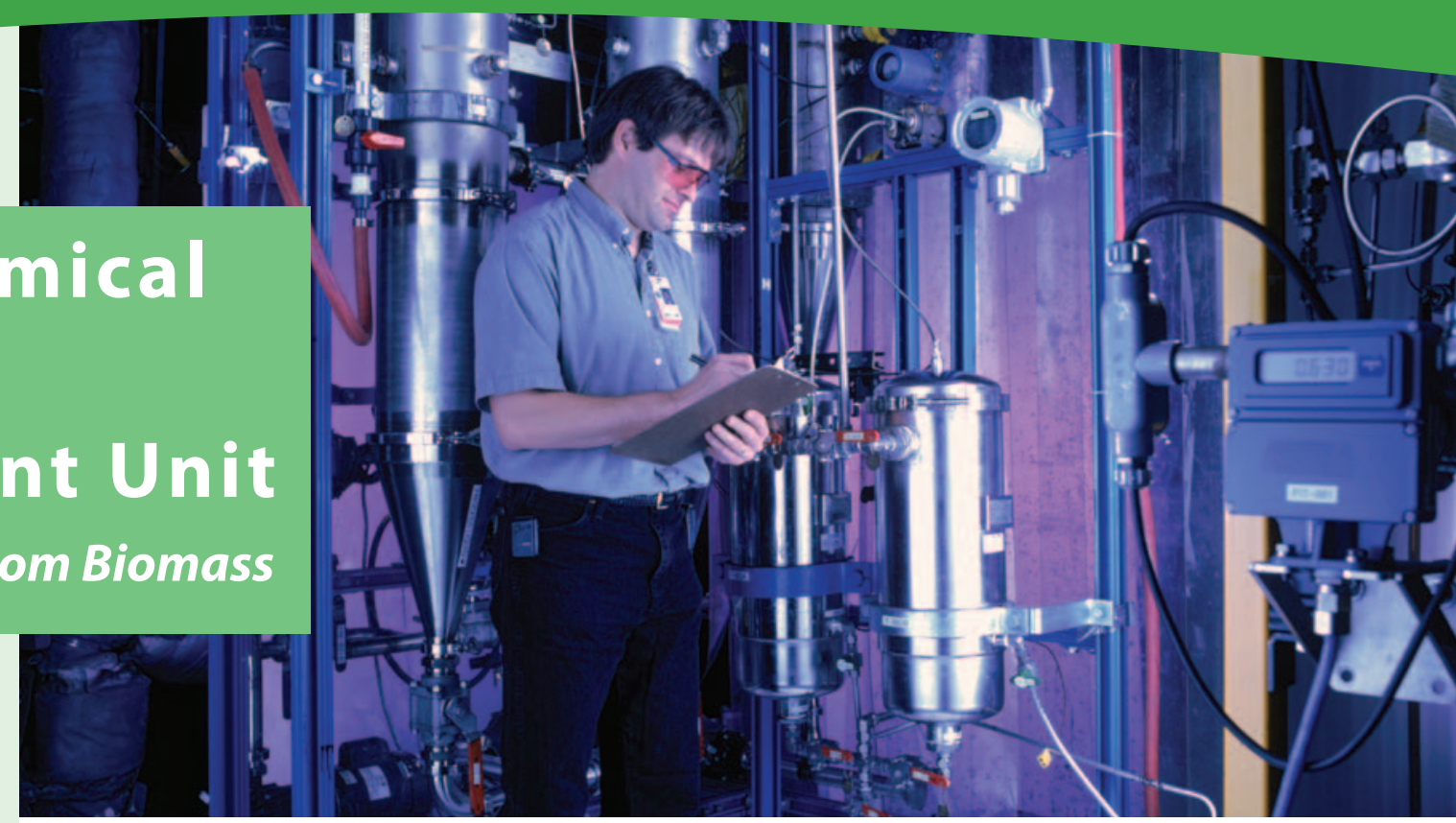

The scrubbers on the TCPDU are used to remove the steam and condensable tars from the synthesis gas.

The Thermochemical Process Development Unit (TCPDU) at the National Renewable Energy Laboratory (NREL) is a unique facility dedicated to researching thermochemical processes to produce fuels from biomass.

Thermochemical processes include gasification and pyrolysis-processes used to convert a wide variety of biomass to liquid fuels, electricity, and other useful products. Located on the Department of Energy's NREL campus in Golden, Colorado, the TCPDU is a pilot-scale conversion plant that can be used by researchers, industry partners, and stakeholders to test a wide variety of potential biomass feedstocks and thermochemical conversion processes and technologies.

\section{Gasification}

Gasification is the process of heating biomass by partial oxidation or in the presence of steam that produces a mixture of carbon monoxide and hydrogen called synthesis gas or syngas. The principal goal of gasification is to create a syngas that meets the specifications of liquid transportation fuels synthesis from widely available biomass. NREL's $R \& D$ is focusing on all aspects of improving the efficiency and reducing the cost of gasification through the fuel synthesis process.

\section{Pyrolysis}

Pyrolysis is the process of heating biomass in the absence of added oxygen. It decomposes the biomass and produces an oil-like liquid called pyrolysis oil. Pyrolysis oil can be refined into transportation fuels. NREL is researching all aspects to improve efficiency and to reduce costs of the pyrolysis-to-fuels process. Fast pyrolysis requires a very high particle-heating rate and a short period of heat transfer to the biomass. The TCPDU provides the necessary environment to facilitate fast pyrolysis in either a fluidized bed or an entrained-flow reactor system.

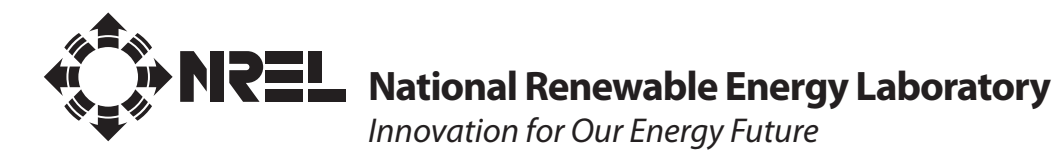




\section{Biomass Conversion via Gasification \\ Gasification \\ Gas Cleaning and \\ Conditioning \\ Fuel Synthesis}

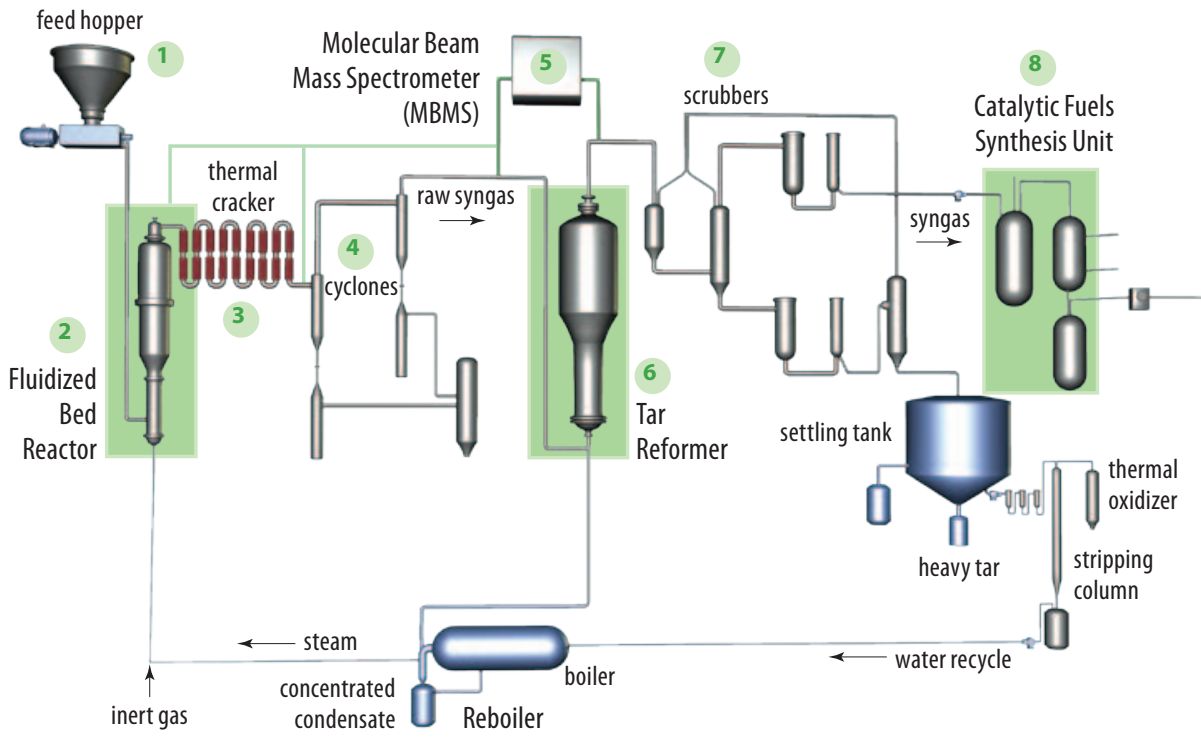

This figure illustrates biomass gasification in a fluidized bed reactor.

This figure illustrates biomass pyrolysis in the entrained-flow reactor. The TCPDU is also capable of pyrolysis in the bubbling-bed reactor.

\section{Biomass Conversion via Gasification}

The NREL TCPDU can be used to convert biomass to liquid fuel via indirect biomass gasification. In this process, biomass pellets are loaded into the ${ }^{1}$ feed hopper and augered into either the fluidized bed or entrained-flow reactor as crushed powder. ${ }^{2}$ In the fluidized bed reactor, the feedstock powder mixes with sand as steam bubbles up through the sand at temperatures between $600^{\circ} \mathrm{C}$ and $800^{\circ} \mathrm{C}$. This causes the biomass to break down into smaller molecules.

\section{Biomass Conversion via Pyrolysis}

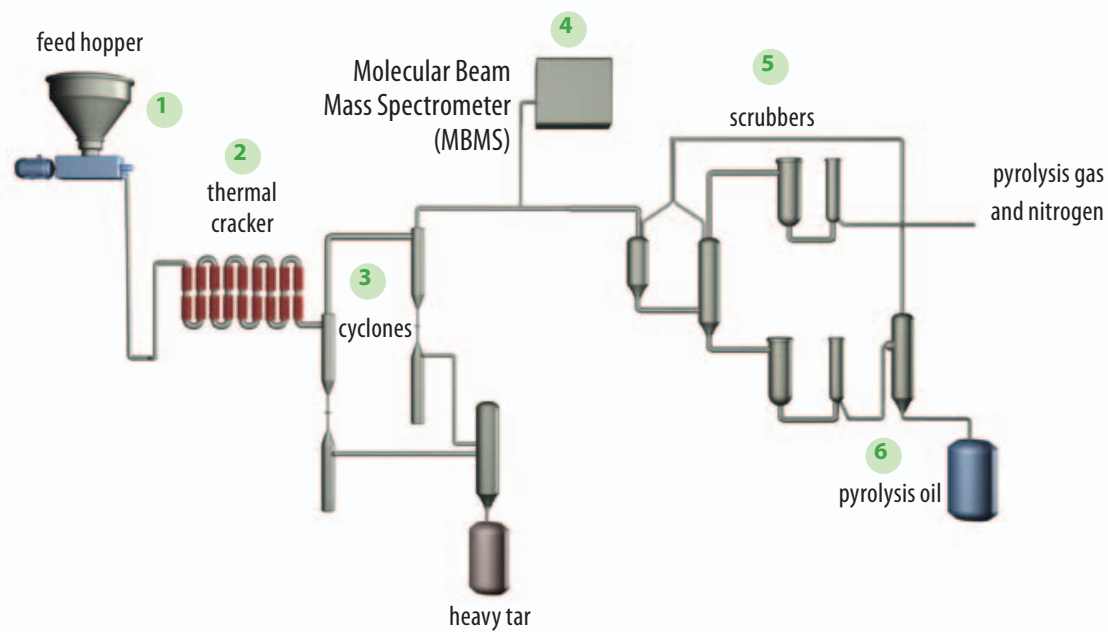

The mixture of solids, vapor, and gas leaves the fluidized bed and moves into the 3 thermal cracker, where intense heat and steam further break down the molecules. At these high temperatures, the syngas components of carbon monoxide and hydrogen form. Unfortunately, the gasification process also forms undesired components like tars that can foul the catalysts; these tars must be removed from the syngas prior to the fuel-synthesis step. The cyclones and tar reformer work together to remove the tars and other solids.

Moving through ${ }^{4}$ the cyclones, the remaining solids are separated from the gas, and a sample of the gas and vapor enters the ${ }^{5}$ molecular beam mass spectrometer for analysis. The remaining gaseous and vapor compounds enter the 6 fluidized bed catalytic tar reformer where they bubble up through a catalyst that converts the tars to additional syngas. As the gas moves from the tar reformer to the scrubber system, another gas sample enters the ${ }^{5}$ mass spectrometer for comparison to the inlet analysis.

After analysis, the hot syngas travels to the 7 scrubber system where it is cooled by a re-circulated liquid and filtered to remove aerosols that form during cooling. The remaining dry gases are compressed and move ${ }^{8}$ to the catalytic fuels synthesis unit. A liquid mixture of oil and catalyst stirring in the synthesis unit completes the syngas conversion to mixed alcohols or other liquid transportation fuels.

\section{Biomass Conversion via Pyrolysis}

The TCPDU can also be configured to create pyrolysis oil, a complex mixture that can be refined into motor fuels. In this process, the biomass feedstock is loaded into the ${ }^{1}$ feed hopper and carried by nitrogen to the ${ }^{2}$ thermal cracker where it is heated in the absence of added oxygen to between $500^{\circ} \mathrm{C}$ and $700^{\circ} \mathrm{C}$. The heat breaks down the biomass into pyrolysis vapor, gas, and char. Nitrogen is used in the process in place of steam to provide the inert environment necessary for effective pyrolysis. 
Next, the ${ }^{3}$ cyclones clean char from the vapor, and, as in the gasification process, the ${ }^{4}$ molecular beam mass spectrometer analyzes the vapor. A cool liquid sprays the pyrolysis vapor as it enters the 5 scrubbers, and the resulting 6 pyrolysis oil condenses at the bottom of the scrubber tanks. The TCPDU

filters and collects the pyrolysis oil. Finally, the pyrolysis oil can be run through a series of reactors to upgrade the pyrolysis oil to a more desirable state. This step is useful to assess stability, acidity, and other properties prior to the final stage to process the oil into a transportation fuel.

\section{Additional Capabilities at the Thermochemical Users Facility}

The TCPDU is housed in the Thermochemical Users Facility (TCUF) on the NREL campus. In addition to the TCPDU, the TCUF contains facilities for catalyst testing and evaluation and a bench-scale reactor for conducting exploratory work.

\section{Bench-Scale Biomass Conversion System}

The bench-scale biomass conversion system is a two-inch-diameter, hightemperature fluidized bed reactor.

Depending on research needs, this reactor can be used for small-scale studies of biomass gasification, pyrolysis, catalytic reforming of pyrolysis vapors, or raw syngas conditioning.

\section{Slip-Stream Catalyst Synthesis Test Cell}

The TCUF's slip-stream catalyst testing cell allows researchers to evaluate fuel-synthesis catalysts using either bottled gases or a slip-stream of biomass-derived syngas from the TCPDU. This test cell houses both fixed and slurry bed reactors for benchscale, fuel-synthesis-catalyst evaluation.

\section{Catalytic Fuel-Synthesis Reactors}

Starting in 2009, the TCUF will include a full-stream, catalytic-fuel-synthesis system that will be capable of converting the full syngas stream from the TCPDU to liquid fuels. Three independent reactors will be able to use the TCPDU syngas stream for testing multiple synthesis catalysts or reactor conditions for comparative fuel synthesis studies.

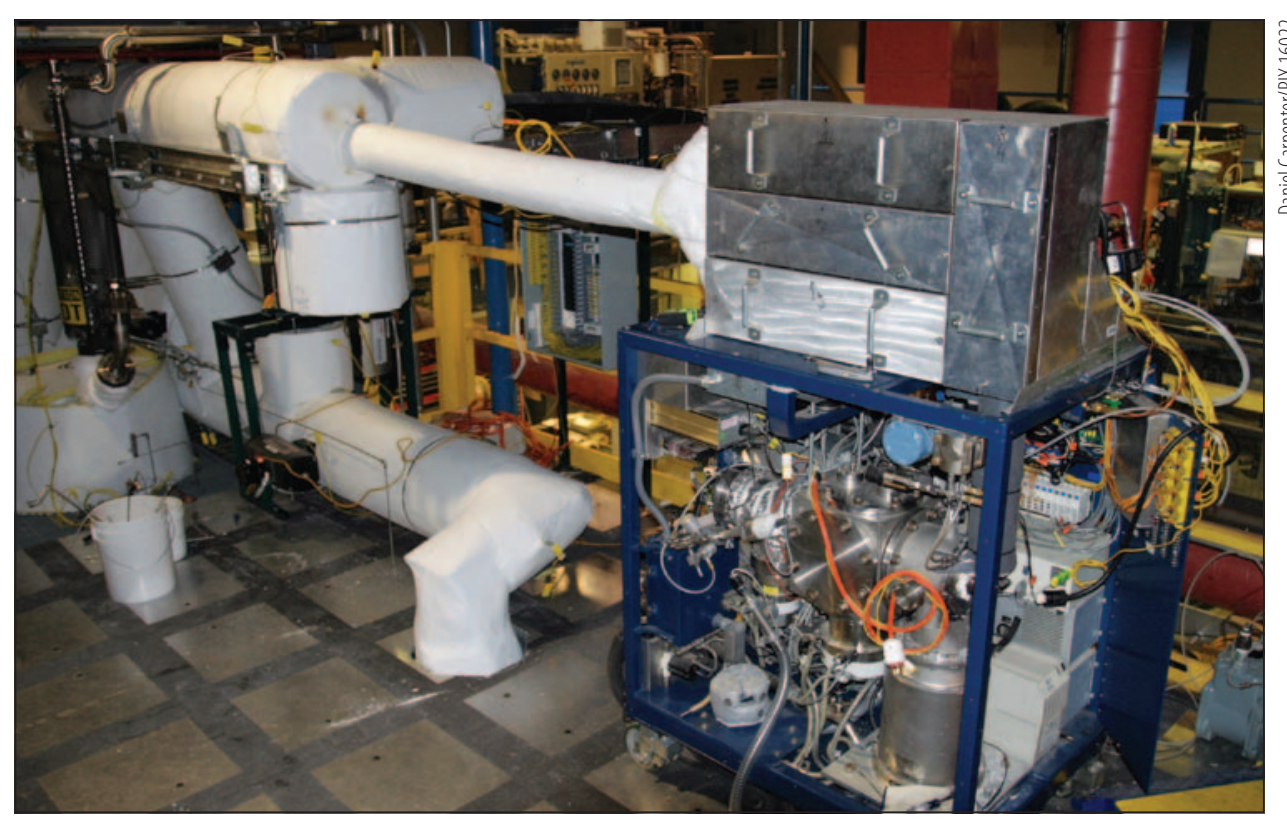

\section{Real-Time Sampling \& Chemical Analysis}

The TCUF laboratories can analyze products on-line over a wide spectrum of chemical compositions. A collection of dedicated, analytical instruments connects to the process with special sampling methods. The analytical equipment used throughout the TCUF includes:

- Molecular beam mass spectrometer

- Three gas chromatographs

- Eight non-dispersive, infrared sensors

- Thermal conductivity detectors

- Paramagnetic $\mathrm{O}_{2}$ sensor

- Two residual-gas analyzers.

The TCUF's analytical capability can also be taken on the road to provide on-line sampling at a customer's site.

\section{Syngas-End-Use Applications}

The thermochemical research group at NREL studies end-use applications for clean syngas including the direct production of liquid transportation fuels, highpurity hydrogen, and other products. Current research is focused on producing ethanol and higher alcohols from biomassderived syngas using catalytic fuel synthesis.

\section{Fuel-Synthesis Chemistry}

The petroleum and petrochemical industries currently use a number of first-generation, commercial catalytic processes for conversion of syngas to fuels and chemicals. Current fuel-synthesis
The Molecular Beam Mass Spectrometer (MBMS) analyzes vapors during the gasification and pyrolysis processes.

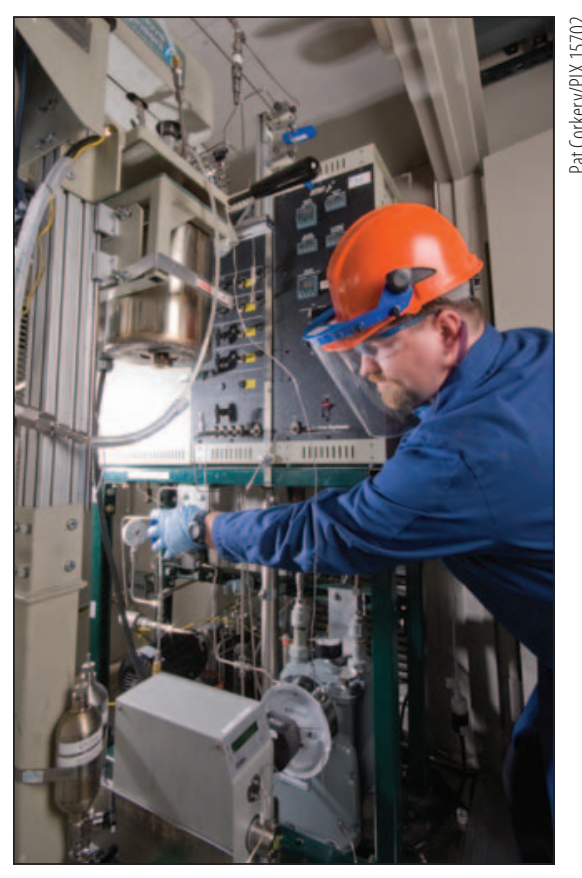

Catalytic fuels synthesis unit converts syngas to liquid fuels such as methanol and mixed alcohols. 
research at NREL includes modifying mixed alcohols catalysts to improve yield and selectivity to desired products.

NREL examines conventional synthesis routes and catalysts employing a microcatalytic reactor system operating on a slipstream of biomass-derived syngas produced in the TCPDU. The syngas slipstream is cleaned and conditioned prior to reaction in order to remove contaminants specific to a given catalytic conversion process. NREL scientists and engineers characterize the products from the catalytic reactor system to determine yield, selectivity, and product quality.

\section{Pyrolysis Oil-End-Use Applications}

NREL is researching production of intermediate and finished products from pyrolysis oil. Researchers on one project are looking at producing a bio-crude with characteristics that would allow it to be processed into transportation fuels using existing petroleum refineries, either as "neat" or as a blend-stock with conventional crude oil. Other researchers are

\section{Contacts}

National Bioenergy Center

Dr. Mike Cleary, Director

National Renewable Energy Laboratory

1617 Cole Blvd., Golden, CO 80401

www.nrel.gov/biomass

Dr. Adam Bratis

Biomass Program Technology Manager (acting)

303-384-7852

adam.bratis@nrel.gov

Dr. Mark Davis

Thermochemical Program Platform Lead 303-384-6140

mark.davis@nrel.gov

Dr. Robert Baldwin, Group Manager Thermochemical Process R\&D and Biorefinery Analysis

303-384-6855

robert.baldwin@nrel.gov

Dr. John Ashworth, NREL Partnership

Development Team Leader

303-384-6858

john.ashworth@nrel.gov

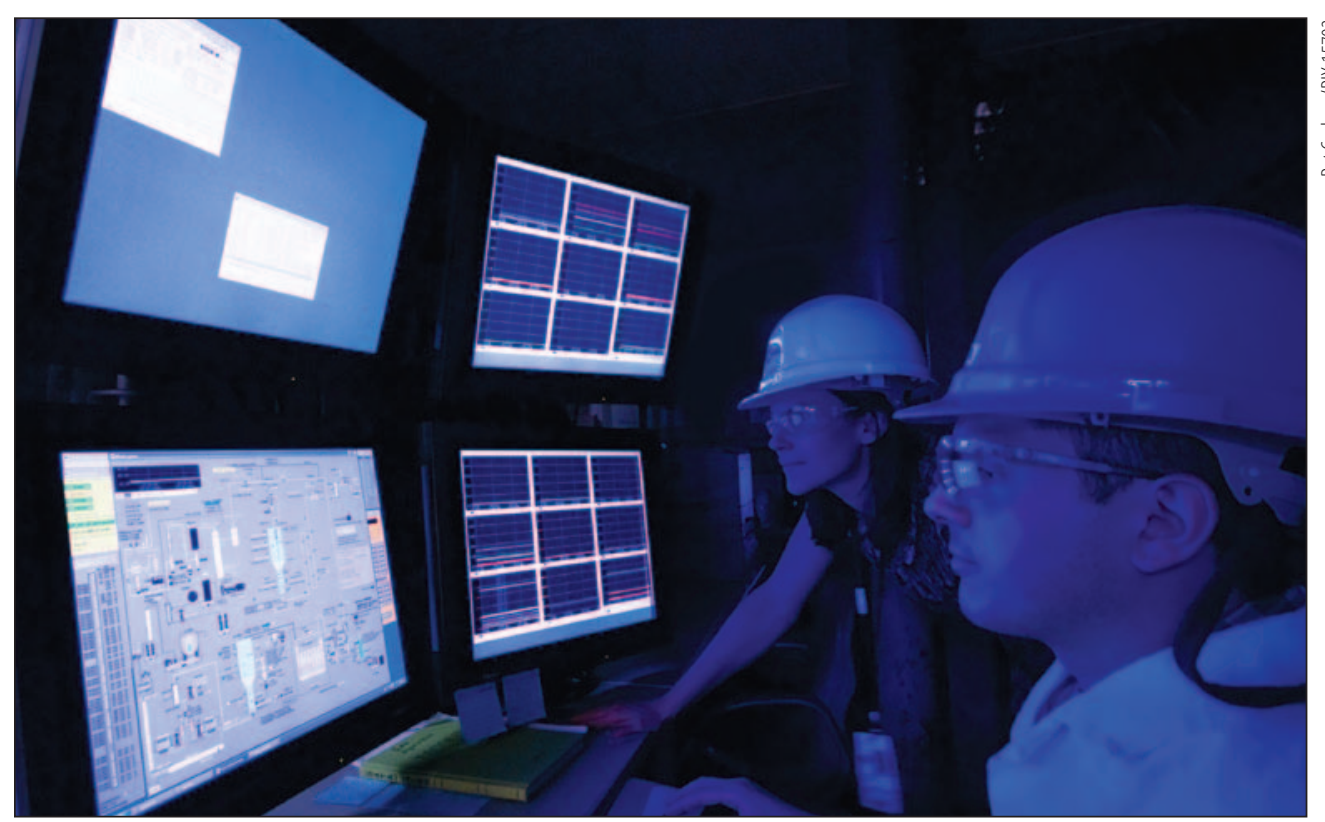

The Thermochemical Users Facility (TCUF) is equipped with sophisticated data monitoring and operation control systems. This control room simultaneously monitors all key operating parameters.

exploring direct-catalytic upgrading of pyrolysis oil to finished fuels.

\section{Working with NREL}

NREL designed the Thermochemical Process Development Unit and other research and analytical capabilities in the Thermochemical Users Facility to assist industry and researchers in developing biomass conversion and utilization technologies. The TCUF is available for experimental investigations of individual unit operations, an entire process, or a new feedstock. The TCPDU operates at a scale that facilitates acquisition of highly accurate material and energy-balance information. In addition, extensive on-line analytical instrumentation allows the effects of feedstock and process operating conditions to be readily determined.

The TCUF capabilities, facilities, technologies, and expertise are available to outside researchers and developers interested in cooperative research and development agreements, work-forothers agreements, licenses, and other collaborative business arrangements. NREL's National Bioenergy Center welcomes inquiries from companies and research institutions interested in using the TCUF process and analytical equipment to develop and commercialize technology to make fuels and other products from biomass.

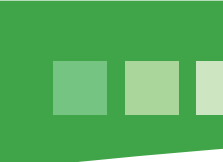

Bioenergy Technologies

\section{National Renewable Energy Laboratory}

1617 Cole Boulevard, Golden, Colorado 80401 303-275-3000 • www.nrel.gov

NREL is a national laboratory of the U.S. Department of Energy Office of Energy Efficiency and Renewable Energy Operated by the Alliance for Sustainable Energy, LLC

NREL/BR-510-44034 • January 2009

Printed with a renewable-source ink on paper containing at least $50 \%$ wastepaper, including $10 \%$ post consumer waste. 